Understanding Molecular Properties 


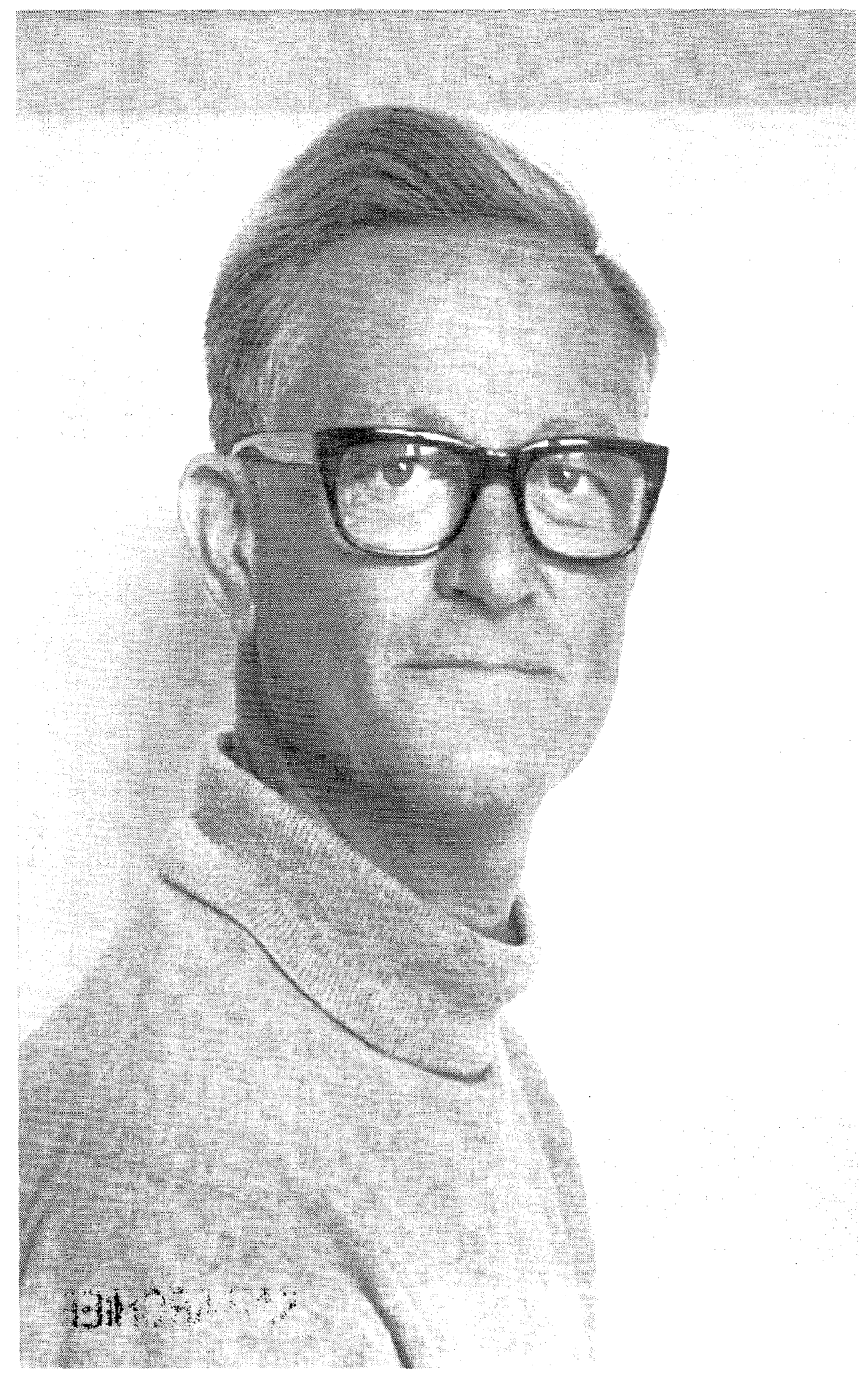

CARL JOHAN BALLHAUSEN 


\section{Understanding \\ Molecular Properties}

A Symposium in Honour of Professor Carl Johan Ballhausen, held at The Royal Danish Academy of Sciences and Letters, April 4 and 5, 1986

\section{Edited by}

John Avery

Department of Physical Chemistry, University of Copenhagen

Jens Peder Dahl

Department of Physical Chemistry,

The Technical University of Denmark, Lyngby

and

Aage E. Hansen

Department of Physical Chemistry, University of Copenhagen

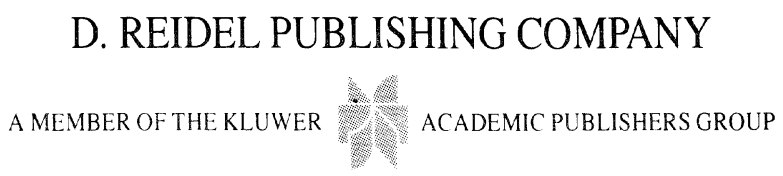

DORDRECHT / BOSTON / LANCASTER / TOKYO 
Library of Congress Cataloging in Publication Data

\section{$\overline{\mathrm{CIP}}$}

Understanding molecular properties.

Includes index.

1. Molecular structure-Congresses. 2. Molecules-Congresses. 3.

Ballhausen, Carl Johan, 1926- -Congresses. I. Ballhausen, Carl

Johan, 1926- . II. Avery, John, 1933- . III. Dahl, Jens Peder.

IV. Hansen, Aage E., 1937-

QD461.U5 $1987 \quad 541.2^{\prime 2} \quad 86-29796$

ISBN-13: 978-94-010-8182-5 e-ISBN-13: 978-94-009-3781-9

DOI: 10.1007/978-94-009-3781-9

Published by D. Reidel Publishing Company,

P.O. Box 17, 3300 AA Dordrecht, Holland.

Sold and distributed in the U.S.A. and Canada

by Kluwer Academic Publishers,

101 Philip Drive, Assinippi Park, Norwell, MA 02061, U.S.A.

In all other countries, sold and distributed

by Kluwer Academic Publishers Group,

P.O. Box 322, 3300 AH Dordrecht, Holland.

All Rights Reserved

(C) 1987 by D. Reidel Publishing Company, Dordrecht, Holland

Softcover reprint of the hardcover 1st edition 1987

No part of the material protected by this copyright notice may be reproduced or utilized in any form or by any means, electronic or mechanical including photocopying, recording or by any information storage and retrieval system, without written permission from the copyright owner 
TABLE OF CONTENTS

Introduction

PART I. ELECTRONIC STRUCTURE OF TRANSITION METAL COMPLEXES

Electronic Spectroscopy of Metal-Metal $\sigma$-Symmetry Interactions, by

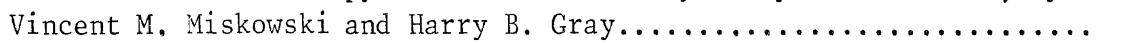

Metal Metal Bonds in Edge Sharing Bioctahedra, by F. Albert Cotton

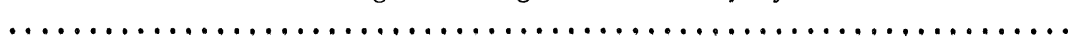

Recent Developments in Inorganic Spectroscopy, by Edward I. Solomon,

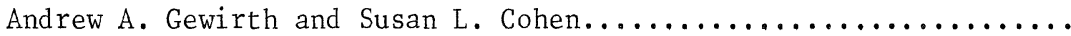

Exchange Effects in Polynuclear Chromium (III) Complexes, by Hans U. Güdel.......................................

Jahn-Teller Distortion of the ${ }^{4} \mathrm{~T}_{1}(\mathrm{G})$ State of $\mathrm{MnCl}_{4}{ }^{2-}$ in $\mathrm{Cs}_{3} \mathrm{MnCl}_{5}$,

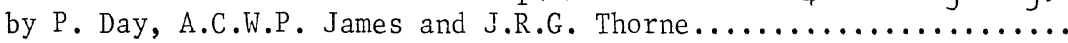

Ab Initio Calculation of Electronic Transitions in Transition

Metal Complexes, by Helge Johansen.................... 95

The Cellular Ligand-Field Model, by M. Gerloch............. 111

The Orthonormal Operator Formulation of Symmetry-Based Ligand Fields, Rhombohedral Hierarchies as a General Example, by Claus Schäffer.. 143

High and Low-Spin Interconversion in a Series of Tris(pyridylmethylamine)iron(II) Compiexes, by Lise Christiansen and Hans Toftlund..

Tetracyanobiimidazole: a Polyploid of Distinction, by Paul G.

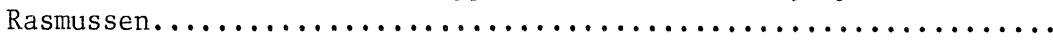

The Intensities of Vibronic Origins in Transition Metal Complex

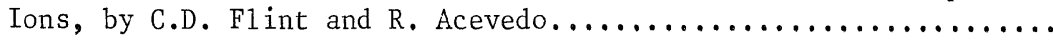

PART II. REACTION RATES

Photon Echoes in Multilevel Systems, by David J. Tannor and Stuart

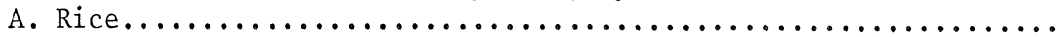

Solvent Dynamical and Symmetrized Potential Aspects of Electron

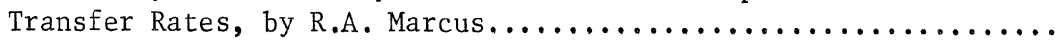


A Theoretical Approach to Chemical Reactions at Solid Surfaces, by

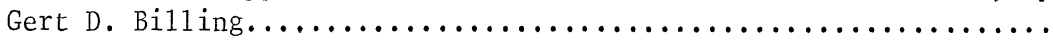

Electron Beams in Surface Analysis, by P.J. M $\phi 11$ er and Finn

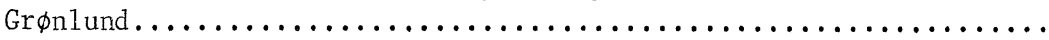

PART III. SPECTROSCOPY

The Spectral Properties of Molecular Propellers, With Applications

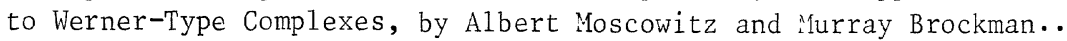

Insights into Hemoglobin Dynamics from Resonance Raman Spectroscopy,

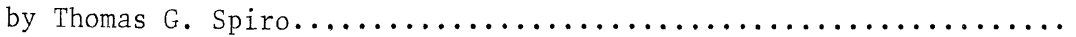

Spin Uncoupling in the $6 \mathrm{~s}$ Rydberg States of Methyl Iodide: The Rotational Sub-Band Structure of the One- and Two-Photon Absorption, by J.A. Dagata, M.A. Scott, W.S. Felps and Sean P.

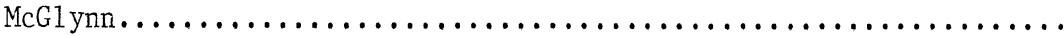

Spectroscopy as a Probe of Intermolecular Interactions, by A.J. McCaffery

Solvent, Temperature, and Band Asymmetry Features of Optical Charge Transfer Transitions in Solute Molecules in Liquids and Glasses, by

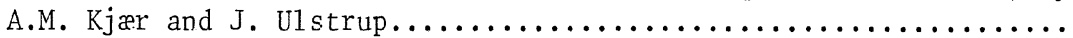

The Theory of Vibrational Optical Activity, by Philip J. Stephens..

Understanding Molecular Optical Activity, by Aage E. Hansen and

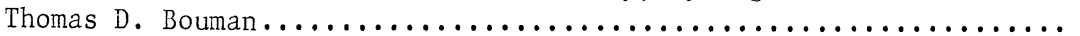

Optical Activity (CD and CPL) as a Probe of Ion Pairing and Solution Structure of Macrocycle Complexes, by R.A. Palmer, R.C. Carter,

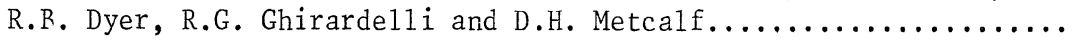

Optical Properties of Large Molecules in the Frenkel Exciton Approximation, by John Avery and Søren Hvidt.................

I'wo-Photon Spectroscopy of Lanthanide (III) Complexes, by W. Strek

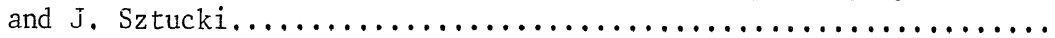

Experimenta1 Research in the Optical Laboratory of Chemical Laboratory IV, H.C. Ørsted Institute, by Ib Trabjerg...........

PART IV. FLOPPY MOLECULES AND THE LIQUID STATE

Molecules: Rigid/Floppy or Solid/Liquid? by R. Stephen Berry..... 
Stability and Conformation of Silicon-Carbon Compounds. A Case Study of $\mathrm{SiC}_{2}, \mathrm{Si}_{2} \mathrm{C}$ and $\mathrm{Si}_{3}$, by Jens Oddershede, John R. Sabin, Geerd H.

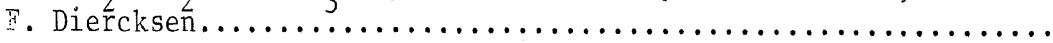

Water and Aqueous Solutions, by Aase Hvidt.

The Effect of Structure and Solvation on the Thermodynamic

Parameters for the Formation of Singly and Doubly Charged Ions of Organic Compounds in Solution, by 01e Hammerich and Vernon D.

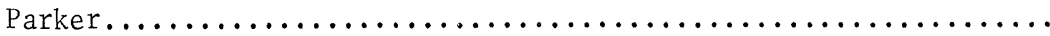

PART V. COMPUTATIONAL QUANTUM CHEMISTRY

The Energies of 3-Electron Atomic Systems Calculated by Hylleraas Type Wave Functions, by K. Hijikata, I. Matsubara and M.

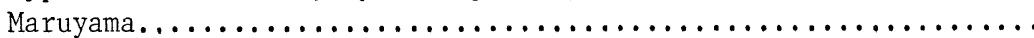

Hartree-Fock Pathology and Large Molecules, by Jean-Louis Calais

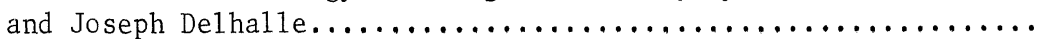

On the Relation Between Relativity and Periodic Trends Within a Triad of Transition Metals, by Tom Ziegler..................

A Symmetric Group Approach to the Calculation of Electronic Correlation Effects in Molecules, by Sten Rettrup, Gian Luigi Bendazzoli, Stefano Evangelisti and Paolo Palmieri..............

Transverse Susceptibility of Spin-S Ising Chains in the Presence

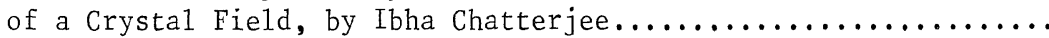

Chemical Bonds and Electronic States of Transition MetalContaining Diatomics, by Irene Shim. 
"Today we realize that the whole of chemistry is one huge manifestation of quantum phenomena."

Carl Johan Ballhausen

\section{INTRODUCTION}

This book presents the proceedings of a symposium on "Understanding Molecular Properties" in honour of Professor Carl Johan Ballhausen. The symposium was held at the Royal Danish Academy of Sciences and Letters, Copenhagen, Denmark, Apri.1 4 and 5, 1986, in connection with Professor Ballhausen's 60th birthday, and in recognition of his important contributions to quantum chemistry.

The distinguished scientists from many parts of the world who have contributed to this book have all, at some time, been associated with Car1 J. Ballhausen's laboratory at the University of Copenhagen. In fact, we prepared the list of invited speakers by going through the laboratory's guest book. The symposium was thus, in a sense, a "family reunion" as well as a scientific meeting.

Many of the contributions deal with a field in which Carl J. Ballhausen was a pioneer - the experimental and theoretical study of transition metal complexes. Experimental work in this field goes back to C.W. Blomstrand and S.M. Jфrgensen, who called attention to seeming1y anomalous compounds of chromium, cobalt and platinum, and to A. Werner, who correctly understood the stereochemistry of these compounds. More recently, experimental work on transition metal complexes has led to a renaissance of inorganic chemistry, through the work of Jannik Bjerrum, Sir Geoffrey Wilkinson, F. Albert Cotton, Harry B. Gray and others.

The theory of transition metal complexes is, of course, an application of quantum theory, for which Copenhagen has a long tradition going back to the pioneering work of Niels Bohr. By 1929, quantum theory was sufficiently developed to account for most of the details of the spectra of free atoms. In that year, Henri Bequerel put forward the idea that the central metal ion in a transition metal complex might be treated as a free ion except for the influence of the electric field due to the charges on the surrounding ligands. The presence of this "crystal field" meant that electrons on the central ion experienced a potential which had, typically, octahedral, tetrahedral or square-planar symmetry rather than spherical symmetry.

In the same year in which Bequerel proposed this model, the symmetry aspects of crystal field theory were treated in a classic paper by Hans Bethe. He had been reading Herman Weyl's book, "The Theory of Groups in Quantum Mechanics", and he took up the problem as an exercise in group theory to make sure that he understood Weyl's book!

Bethe's pioneering work was carried farther by Robert Schlapp, W.G. Penney and especially by J.H. Van Vleck. The applications of crystal field theory to magnetism were developed by Van Vleck in his important book, "The Theory of Electric and Magnetic Susceptibilities", which was published in 1932 .

In 1935, E.U. Condon and G.H. Shortley published their classic work, 
"The Theory of Atomic Spectra", summarizing all that was then known about the quantum theory of free atoms; and in 1961, J.S. Griffith published "The Theory of Transition Metal Ions", in which he combined the ideas in Condon and Shortley's book with those of Bethe, Schlapp, Penney and Van Vleck. All this work, however, was done by physicists, and the results were reported in a way which was more accessable to physicists than to chemists.

In the meantime, Car1 J. Ballhausen had been studying quantum theory with W. Moffitt at Harvard; and in 1962 (almost simultaneously with Griffith) he published his extremely important book, "Introduction to Ligand Field Theory". This influential book was written from the standpoint of a chemist, and it became the standard work from which chemists learned the quantum theory of transition metál complexes.

While it treated in detail the group theoretical aspects of crystal field theory, Carl J. Ballhausen's book also emphasized the limitations of the theory. As he pointed out, it is often not sufficient to treat the central metal ion as free (apart from the influence of the charges on the surrounding ligands): - In many cases hybridization of metal and ligand orbitals is significant. Thus, in general, a molecular orbital treatment is needed to describe transition metal complexes. However, much of the group theory developed in connection with crystal field theory can also be used in the molecular orbital treatment.

The improved theory, which took metal-1igand hybridization into account, became known as "ligand field theory". It was applied to compound after compound by Carl J. Ballhausen and his coworkers, in more than 100 research papers. Carl J. Ballhausen's pedagogical activities (such as his three papers in the Journal of Chemical Education, Vo1. 56, 1979) have also had an important effect in making ligand field theory known to chemists. Finally, we should mention his more recent books, "Molecular Orbital Theory" (with Harry B. Gray, 1964), "Molecular Electronic Structures of Transition Metal Complexes" (1979) and "Molecular Electronic Structures" (with Harry B. Gray, 1980). All of these works have had a great influence on theoretical chemistry.

Not all of the articles in this book are devoted to ligand field theory. Among the other topics treated are reaction rates, spectroscopy, floppy molecules and the liquid state, and computational quantum chemistry. However, in dealing with these varied topics, all of the authors have tried to deepen our understanding of molecular properties, and to show how the underlying and unifying quantum theory can be used to interpret and predict the varied experimentally observable characteristics of molecules. We feel that this is in the spirit of the quotation with which we began the introduction.

We take pleasure in dedicating this book to Professor Carl Johan Ballhausen on the occasion of his 60th birthday, as a tribute to his important contributions to theoretical chemistry. We would also like to thank the distinguished scientists from four continents who have contributed to this book, and who join us in this tribute.

John Avery, Jens Peder Dahl and Aage E. Hansen, Copenhagen, 1986 